\title{
EFFECTS OF PALYTOXIN ON ISOLATED INTESTINAL AND VASCULAR SMOOTH MUSCLES
}

\author{
Katsuaki ITO, Hideaki KARAKI, Yukisato ISHIDA, \\ Norimoto URAKAWA and Takehiko DEGUCHI* \\ Department of Veterinary Pharmacology, Faculty of Agriculture, \\ University of Tokyo, Bunkyo-ku, Tokyo 113, and ${ }^{*}$ Central Research \\ Laboratories, Sankyo Co. Ltd., Shinagawa-ku, Tokyo 140, Japan
}

Accepted July 15, 1976

\begin{abstract}
Palytoxin (PTX), the most potent marine toxin isolated from the Zoanthid, Palythoa tuberculosa, was studicd to determine the effect on isolated smooth muscles. In guinca pig taenia coli PTX at above $3 \times 10^{-10} \mathrm{~g} / \mathrm{ml}$ caused a contraction which slowly subsided under isotonic recording. Under isometric recording PTX at above $1 \times 10^{-10}$ $\mathrm{g} / \mathrm{ml}$ caused a contraction which depended on the spontaneous activity. The PTXinduced contraction was not affected by atropine, tripelennamine or tetrodotoxin but was inhibited by $5 \mathrm{mM} \mathrm{Mg}$, norepinephrine, isoprenaline or papaverine. PTX at above $\mathrm{I} \times 10^{-9} \mathrm{~g} / \mathrm{ml}$ induced an increase in spike frequency and a slight depolarization accompanied with a contraction when measured using a sucrose gap method. In some cases the spike generation was almost abolished after a long exposure to higher dose of PTX and the developed tension gradually decreased. Under isometric recording, PTX caused a sustained contraction in rabbit aorta, dog mesenteric and coronary arterics at above $1 \times 10^{-10}, 1 \times 10^{-10}$ and $1 \times 10^{-11} \mathrm{~g} / \mathrm{ml}$, respectively, in a dosedependent manner. The coronary artery was most sensitive among the preparations used. PTX-induced contraction in aorta was irreversible, was not influenced by phentolamine but diminished with $5 \mathrm{mM} \mathrm{Mg}$ and disappeared in a D-600 or Ca-free medium. PTX is thus an extremely potent and direct stimulant which acts on smooth muscles.
\end{abstract}

A highly toxic substance extracted from the Zoanthid, Palythoa tuberculosa, by Kimura and Hashimoto $(1,2)$ is considered to be the cause of ciguatera-like poisoning by a filefish, Alutera scripta, in the Ryukyu Islands (1).

On the other hand, Ciereszko et al. (3), and independently Moore and Scheuer (4) found a toxin from Palythoa spp.; P. caribaeorum and P. mammilosa in the Carribean sea, and $P$. vestis and $P$. toxica in the Hawaiian sea, respectively. These toxins were designated as Palytoxin (4) or Palythoatoxin (5). The chemical properties of these substances were similar and it was considered that they were identical or at least closely related substances (2).

Palytoxin (PTX) has an LD 50 of $0.53 \mu \mathrm{g} / \mathrm{kg}$ (in mice; i.v.) (6) and the toxicity is the most potent among the known marine toxins $(6,7)$.

In a previous report, the general pharmacology of PTX was described $(5,6)$; in the anesthetized cat i.v. injection of $0.2 \mu \mathrm{g} / \mathrm{kg}$ PTX caused a rise in the arterial blood pressure followed by a gradually decrease and bradycardia, ectopic beats, bigeminal pulses and $\mathrm{T}$ inversion followed by a cardiac arrest were observed in the ECG. PTX caused a positive inotropic effect followed by depression in the atria and papillary muscle of the guinea pig. In the phrenic nerve-diaphragm preparation of the mouse, PTX depressed the contraction 
by indirect stimulation accompanied with a contracture. It induced a contracture in the frog rectus muscle, and depolarization in the sartorius muscle which was prevented in a low Na medium and diminished by tetrodotoxin.

Other investigations were performed on the circulatory system $(8,9,10)$, however, there is no available data on the effect of PTX on smooth muscle preparations except that PTX causes a contraction in guinea pig ileum $(5,6)$.

In the present work, the mechanical activity in intestinal and vascular smooth muscles was studied using the Magnus method and for the electrical activity in intestinal smooth muscle, a sucrose gap apparatus was used.

\section{MATERIALS AND METHODS}

The ileum and taenia coli were isolated from male guinea pigs weighing 250-300 g. Isotonic shortening of the ileum and the taenia coli were registered on a kymograph with a frontal writing lever or on a pen-writing oscillograph via an isotonic transducer. Taenia coli was preliminarily conditioned with hypertonically added $40 \mathrm{mM} \mathrm{K}$ once before PTX was applied for the purpose of obtaining a reproducible response. Isometric contraction of taenia coli was recorded on a pen-writing oscillograph with a strain gauge transducer.

The membrane potential of the taenia coli was measured using the sucrose gap method as described by Bülbring and Burnstock (11), with a modified apparatus. The chamber was divided into three portions; the Tyrode solution portion was $7 \mathrm{~mm}$ in diameter except for the bottom portion which was $1 \mathrm{~mm}$ to allow for free spontaneous contraction of the muscle. The Tyrode solution was introduced into the chamber from the lower opening and overflowed from the upper edge of the portion so as to maintain the constant level of the Tyrode solution. Artifacts due to level change were thus avoided. The depolarizing $\mathrm{KCl}$ portion of the chamber was filled with $160 \mathrm{mM} \mathrm{KCl}$ agar and one end of the muscle was fixed herein (12). The central part of the muscle was perfused with sucrose solution which had been passed through a deionizing resin immediately before use. The recording electrode was embedded in $\mathrm{KCl}$-agar of the depolarized portion and the indifferent electrode was inserted into the Tyrode portion.

Rabbits of either sex weighing $1500-2000 \mathrm{~g}$ were sacrificed by injecting air to produce embolism and thoracic aortas were then isolated. The adventitia was removed. Mongrel dogs of either sex weighing 9-15 kg were bled under pentobarbital anesthesia and left circumflex of coronary artery and mesenteric artery were excised. Helical strips about $20 \mathrm{~mm}$ length were made from each artery and tension was recorded isometrically.

Modified Tyrode solution used contained (mM) NaCl 136.8, $\mathrm{KCl} 5.4, \mathrm{CaCl}_{2} 2.5, \mathrm{MgCl}_{2}$ 1.0, $\mathrm{NaHCO}_{3} 11.9$ and glucose 5.5 aerated with $95 \% \mathrm{O}_{2}$ and $5 \% \mathrm{CO}_{2}$ at $37{ }^{\circ} \mathrm{C}$. Hypertonically added 15,40 or $60 \mathrm{mM}$ potassium $(\mathrm{H} 15 \mathrm{~K}, \mathrm{H} 40 \mathrm{~K}, \mathrm{H} 60 \mathrm{~K})$ medium was made by adding $\mathrm{KCl}$ crystals to Tyrode solution to make a final concentration of $20.4,45.4$ or 65.4 $\mathrm{mM} \mathrm{KCl}$.

The $\mathrm{Ca}$-free solution was prepared by omitting $\mathrm{CaCl}_{2}$ from Tyrode solution with or without $1 \mathrm{mM}$ EGTA. 
PTX extracted from Palythoa tuberculosa and having an LD50 value of $0.53 \mu \mathrm{g} / \mathrm{kg}$ (i.v. in mice) was kindly donated by Prof. Y. Hashimoto of the University of Tokyo. The toxin was dissolved in distilled water at a concentration of $1 \times 10^{-5} \mathrm{~g} / \mathrm{ml}$ and kept frozen as stock solution. The stock solution was appropriately diluted just before use.

Drugs used were atropine sulfate (E. Merck AG), chlorpheniramine maleate (Sankyo Co.), tetrodotoxin (Sankyo Co.), tripelennamine hydrochloride (Ciba-Geigy (Japan)), phentolamine mesylate (Ciba-Geigy (Japan)), papaverine hydrochloride (Tokyo Kasei Co.), 1-norepinephrine bitartrate (Wako Pure Chemical Co.), isoprenaline hydrochloride (Tokyo Kasei Co.), D-600 hydrochloride (Knoll AG) and adenosine (Tokyo Kasei Co.),

\section{RESULTS}

\section{Effects of PTX on the mechanical activity of ileum and taenia coli of guinea pig}

PTX caused a shortening in guinea pig ileum when recorded isotonically. The shortening was transient, had two peaks each of which was dose-dependent and subsided in several minutes. The response was not affected by $1.5 \times 10^{-5} \mathrm{M}$ atropine or $3.7 \times 10^{-7} \mathrm{M}$ chlorpheniramine. These results confirmed our previous data (6).

Under isotonic recording, taenia coli was previously conditioned with $\mathrm{H} 40 \mathrm{~K}$ and 30 min after removal of H40K PTX was applied. The muscle showed a rapid shortening which was sustained in the presence of $\mathrm{H} 40 \mathrm{~K}$ and was rapidly relaxed by removal of $\mathrm{H} 40 \mathrm{~K}$. PTX at above $3 \times 10^{-10} \mathrm{~g} / \mathrm{ml}$ also induced a contraction but such was slow to develop compared

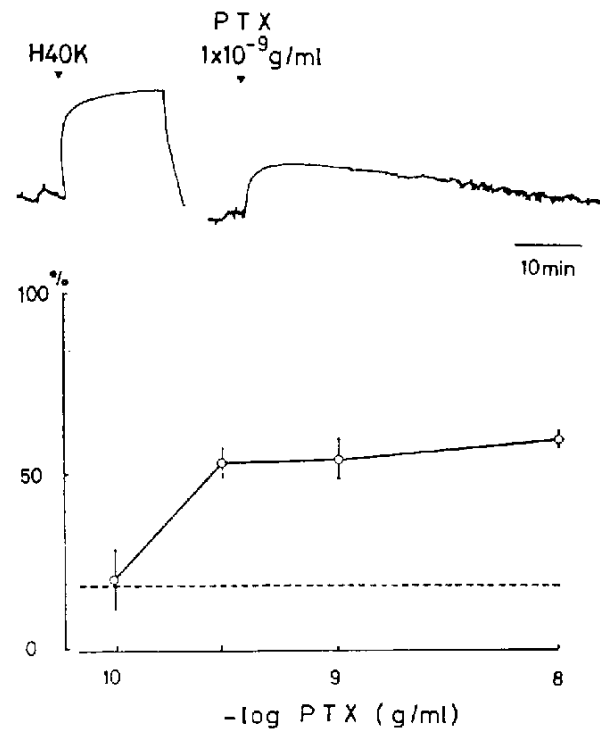

FIG. 1. Isotonic shortening induced by PTX in taenia coli. The muscle was conditioned preliminarily by $\mathrm{H} 4 \mathrm{OK}$ as shown in left of the upper trace. The shortening induced by $1 \times 10^{-9} \mathrm{~g} / \mathrm{ml}$ PTX was shown at right of the upper trace. The lower trace shows dose-response relation for PTX-induced shortening. The maximal shortening induced by $\mathrm{H} 4 \mathrm{OK}$ was expressed $100 \%$ in ordinate. $0 \%$ in ordinate indicates the Ca-free level and the dotted line indicates the resting level just before PTX adding. Vertical lines in the figure indicate standard error. 
with that induced by $\mathrm{H} 40 \mathrm{~K}$ and the peak was reached within $10 \mathrm{~min}$ and gradually declined thereafter to the original length as shown in Fig. 1. Removal of PTX during PTX contraction did not abruptly relax the muscle. PTX, $1 \times 10^{-10} \mathrm{~g} / \mathrm{ml}$, did not cause significant shortening and $3 \times 10^{-10} \mathrm{~g} / \mathrm{ml}$ PTX caused a nearly maximum shortening which was about $50 \%$ of maximum shortening induced by $\mathrm{H} 40 \mathrm{~K}$. The contractile response to PTX between $1 \times 10^{-10}-1 \times 10^{-8} \mathrm{~g} / \mathrm{ml}$ is also shown in Fig. 1 .

Under isometric recording, taenia coli showed different types of spontaneous activity. The first type was more than one gram in amplitude and appeared at a frequency of 0.1-1/ min. Such has been classified by Golenhofen and Loh (13) as minute rhythm contraction. In this preparation $1 \times 10^{-10}-3 \times 10^{-8} \mathrm{~g} / \mathrm{ml}$ PTX caused a contraction. The contraction was phasic, that is similar or slightly larger than the spontaneous contraction, followed by a tonic contraction which gradually declined as shown in Fig. 2a. No dose-response relation was obtained and the response depended on the spontaneous contraction as shown in Fig. 3. Correlation coefficient between peak amplitude in the response to PTX and in the spontaneous contraction was 0.908 .

Other types of spontaneous activity, less active and not showing minute rhythm contraction, were repetitive contractions of below $0.5 \mathrm{~g}$ in amplitude without a quiescent period. In this type preparation, $1 \times 10^{-10}-1 \times 10^{-7} \mathrm{~g} / \mathrm{ml}$ PTX caused a contraction which was small as compared with that in a muscle showing the minute rhythm contraction as shown in

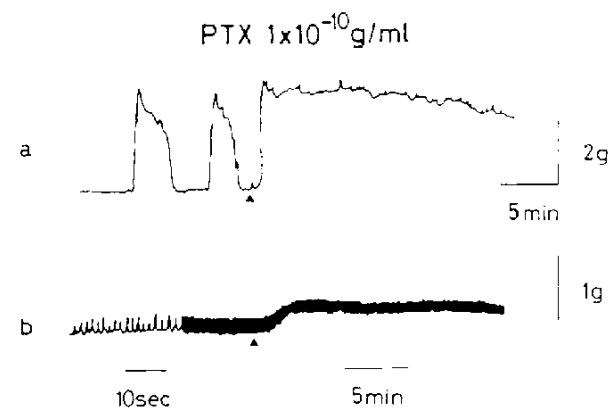

FIG. 2. Isometric contraction of guinca pig taenia coli induced by $11^{-10} \mathrm{~g}$ ml PTX. Fig. 2-a is a sample record in a preparation showing spontaneous contraction of minute rhythm. Fig. $2-b$ is a sample record in a preparation not showing minute rhythm contraction.

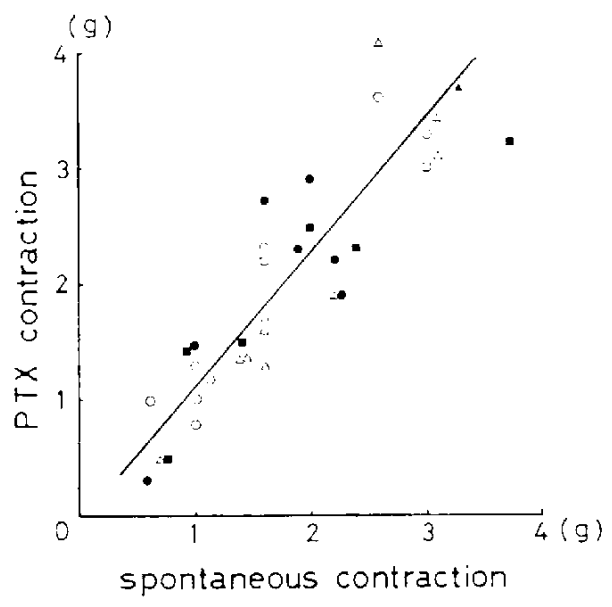

FIG. 3. Relation between the peak amplitude of PTX response and of spontancous contraction in the preparations showing minute rhylhm contraction. $\triangle ; 1 \div 10^{-10}$ $-5: 10^{-10} \mathrm{~g} \mathrm{nol} \mathrm{PTX,} \mathrm{.} \mathrm{:} 1: 10^{-9} 5$. $10^{-9} \mathrm{~g}$ ml PTX, - ; above $110^{-8} \mathrm{~g} \mathrm{~m}$ ! PTX. Regressive line in the figure is calculated from these plots. The correlation coefficient was $0.908 . \square ; 1 \times 10^{-4}$ $\mathrm{g} / \mathrm{ml}$ PTX in the presence of $3 \times 10^{-6} \mathrm{M}$ atropine, $: 1 \% 10^{-9} \mathrm{~g} / \mathrm{ml}$ PTX in the presence of $61^{\prime} \mathrm{M}$ tetrodotoxin. 
Fig. 2b. Some preparations with no spontaneous activity exhibited no response to PTX. The tension development induced by PTX in the preparations not showing minute rhythm contraction was $0.23 \pm 0.08 \mathrm{~g}$ (mean $\doteq$ S.E.; $\mathrm{n}=11$ ) at $1 \times 10^{-10} \mathrm{~g} / \mathrm{ml}, 0.63 \pm 0.22 \mathrm{~g}(\mathrm{n}=7)$ at $1 \times 10^{-9} \mathrm{~g} / \mathrm{ml}$ and $0.87 \pm 0.23 \mathrm{~g}(\mathrm{n}=6)$ at $1 \times 10^{-9} \mathrm{~g} / \mathrm{ml}$ PTX. The differece between the response at $1 \times 10^{-10} \mathrm{~g} / \mathrm{ml}$ and $1 \times 10^{-9} \mathrm{~g} / \mathrm{ml}$ was significant $(\mathrm{P}<0.001)$.

Removal of PTX during PTX contraction did not restore the tension to the control level. When the contraction with PTX in a concentration higher than $1 \times 10^{-8} \mathrm{~g} / \mathrm{ml}$ had subsided, a second application of PTX never resulted in a contraction. However, when the concentration of the toxin in the first application was below $1 \times 10^{-9} \mathrm{~g} / \mathrm{ml}$, the second application induced a small contraction.

Effects of various drugs and ions on the isometric contraction induced by PTX in taenia coli

Pretreatment with $3 \times 10^{-6} \mathrm{M}$ atropine, $6 \times 10^{-7} \mathrm{M}$ tetrodotoxin or $3 \times 10^{-6} \mathrm{M}$ tripelennamine scarcely modified either the spontaneous contraction of taenia coli or the PTXinduced contraction. Fig. 3 shows the response to $1 \times 10^{-8} \mathrm{~g} / \mathrm{ml}$ PTX in the presence of atropine or tetrodotoxin.

$2.5 \times 10^{-5} \mathrm{M}$ papaverine abolished the spontaneous contraction, and the application of $1 \times 10^{-9} \mathrm{~g} / \mathrm{ml}$ PTX after $30 \mathrm{~min}$ preincubation with papaverine caused no contraction. Application of $3 \times 10^{-7} \mathrm{M}$ norepinephrine or $5 \times 10^{-7} \mathrm{M}$ isoprenaline after the tension development by $1 \times 10^{-9} \mathrm{~g} / \mathrm{ml}$ PTX rapidly lowered the tension to the control level.

Pretreatment of the muscle with 5 $\mathrm{mM} \mathrm{Mg}$ for 15 min which abolished the spontancous contraction prevented or depressed a contraction due to $1 \times 10^{-9}$ $\mathrm{g} / \mathrm{ml}$ PTX. After removal of PTX and excess $\mathrm{Mg}$, a contraction occurred as shown in Fig. 4. Adding $5 \mathrm{mM} \mathrm{Mg}$ after the tension development by $1 \times 10^{-9} \mathrm{~g} / \mathrm{ml}$ PTX lowered the muscle tension to the control level. A contraction was restored

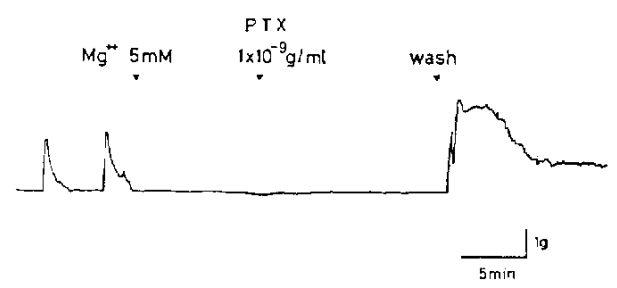

FIG. 4. Inhibition of $1 \times 10^{-8} \mathrm{~g} / \mathrm{ml}$ PTXinduced contraction by treatment of 5 $\mathrm{mM} \mathrm{Mg}$ and appearance after removal of excess $\mathrm{Mg}$ and PTX. by the removal of excess $\mathrm{Mg}$ and PTX from the bathing medium.

Pretreatment of the muscle with $1 \times 10^{-6} \mathrm{M}$ D-600, an organic Ca antagonist (14), which abolished the spontaneous contraction prevented a contraction due to $1 \times 10^{-9} \mathrm{~g} / \mathrm{ml}$ PTX. In the Ca-deficient medium, the spontaneous contraction disappeared after a transient contraction and application of $1 \times 10^{-9} \mathrm{~g} / \mathrm{ml}$ PTX after $30 \mathrm{~min}$ induced no contraction.

In $\mathrm{H60K}$ medium, the cell membrane of taenia coli was depolarized and the muscle exhibited the sustained tension development. Application of $1 \times 10^{-8} \mathrm{~g} / \mathrm{ml}$ PTX in the presence of $\mathrm{H} 60 \mathrm{~K}$ did not induce further contraction.

\section{Changes in membrane potential of taenia coli muscle by PTX}

The membrane potential and mechanical activity in the taenia coli were simultaneously observed with the sucrose gap method. 


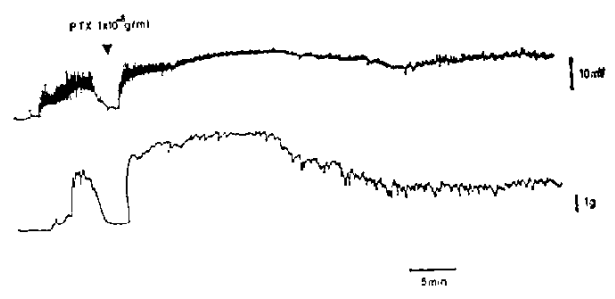

FIG. 5. Changes in membrane potential and tension of guinea pig taenia coli showing spontaneous contraction of minute rhythm. Mechanical activity was recorded isometrically. Upper trace shows the membrane potential and lower trace shows the tension. At the triangle mark $1 \times 10^{-8} \mathrm{~g}$ ml PTX was added.

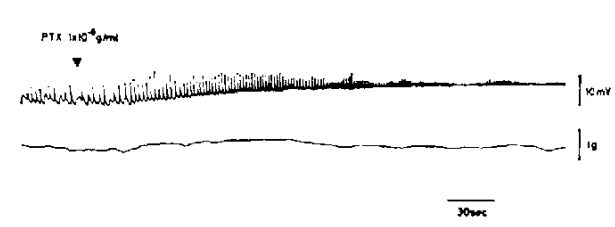

FIG. 6. Changes in membrane potential and tension of taenia coli not showing minute rhythm contraction. Upper trace indicates the membrane potential and lower trace indicates the tension.

In the muscle showing the minute rhythm contraction, $1 \times 10^{-9}$ or $1 \times 10^{-8} \mathrm{~g} / \mathrm{ml}$ PTX induced an increase in spike frequency and depolarization accompanied with tension development as shown in Fig. 5. The magnitude of depolarization due to PTX was similar or slightly larger than that observed during spontaneous contraction, which was usually $5-10 \mathrm{mV}$ in the present experiment. In many cases, the spike discharges were then decreased while depolarization remained. At a higher dose of PTX, $1 \times 10^{-9} \mathrm{~g} / \mathrm{ml}$, the decrease of spike activity was pronounced. In some cases the spike configuration became small and complex or aborted and eventually spike generation ceased. After a long exposure to PTX, the membrane potential gradually increased accompanied with a tension decline. The second application of PTX caused no change either in membrane potential or in mechanical response.

In the muscle showing repetitive spike activity, $1 \times 10^{-8} \mathrm{~g} / \mathrm{ml}$ PTX increased the spike frequency and depolarized the membrane slightly as shown in Fig. 6.

When $\mathrm{H} 15 \mathrm{~K}$ was added to the medium the membrane of muscle was depolarized by 10-18 $\mathrm{mV}$ and spike frequency increased. The depolarization induced by PTX was always smaller than that induced by $\mathrm{H} 15 \mathrm{~K}$ in the same preparation.

When the mechanical activity was recorded isotonically, PTX caused an increase of spike discharge and depolarization in all preparations used followed by occasional decrease in spike activity.

\section{Effects of PTX on the isolated rabbit aorta}

A strip of rabbit aorta was preliminarily conditioned by H60K and PTX was then applied. PTX induced a slowly developing contraction in a dose dependent manner (Fig. 8) in rabbit aorta. The rate of rise in PTX-induced contraction was slower than that of $\mathrm{H} 60 \mathrm{~K}$ as shown in Fig. 7a. At a dose of PTX above $3 \times 10^{-9} \mathrm{~g} / \mathrm{ml}$, the muscle attained the peak tension within $15 \mathrm{~min}$ and sustained this level for more than $1 \mathrm{hr}$. The highest dose, $3 \times 10^{-8} \mathrm{~g} / \mathrm{ml}$, of PTX contracted the muscle to the level induced by $\mathrm{H} 60 \mathrm{~K}$ followed by a slow decline in the presence of PTX, in some cases. At the lower doses, a longer time was needed for the 


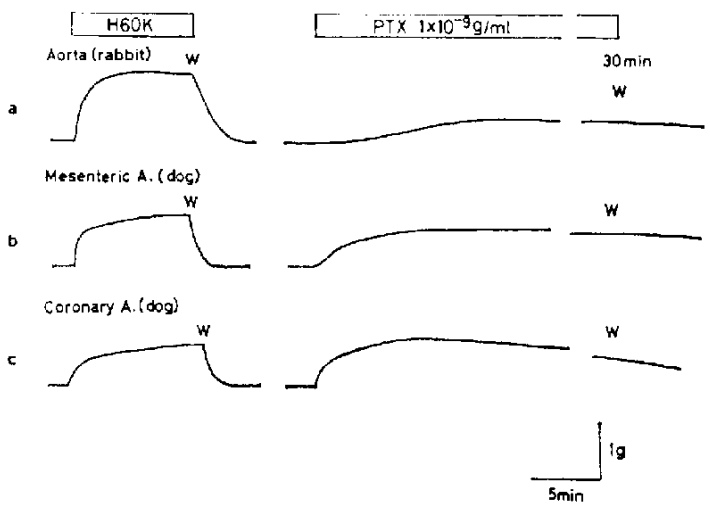

FIG. 7. Contractions induced by $1 \times 10^{-9} \mathrm{~g} / \mathrm{ml} \mathrm{PTX}$ in rabbit aorta (a), dog mesenteric artery (b) and dog coronary artery (c). The muscles were preliminarily conditioned with $\mathrm{H} 6 \mathrm{OK}$ which was shown at Jeft for comparison. (W) indicates washing out of stimulants. In rabbit aorta and dog mesenteric artery PTX caused a sustained contraction lasting for more than $1 \mathrm{hr}$. In dog coronary artery $1 \times 10^{-9} \mathrm{~g} / \mathrm{ml}$ PTX caused a contraction which reached the pcak in $10 \mathrm{~min}$ followed by slow relaxation. Each contraction was not altered by washing out of PTX (W) from the bath.

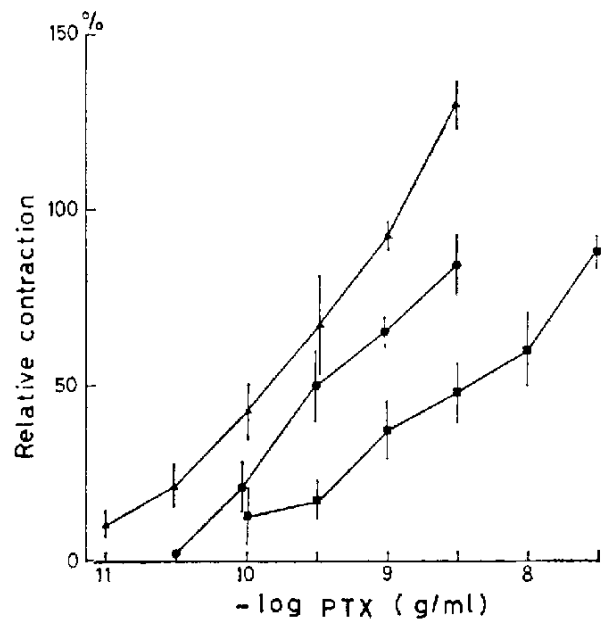

FIG. 8. Dose-response relation for the contraction in rabbit aorta $\square-\square, \operatorname{dog}$ mesenteric artery and dog coronary artery

Vertical bars represent the standard error. $100 \%$ in ordinate represents the maximal contraction in each artery induced by H6OK.

muscle to reach the peak of contraction, i.e., about $1 \mathrm{hr}$ at a concentration of $1 \times 10^{-10} \mathrm{~g} / \mathrm{ml}$. The aorta did not readily relax with removal of PTX from the bath.

Post-treatment with $2 \times 10^{-6} \mathrm{M}$ phentolamine, phenoxybenzamine or $3 \times 10^{-6} \mathrm{M}$ atropine did not affect $3 \times 10^{-9} \mathrm{~g} / \mathrm{ml}$ PTX-induced contraction. Addition of $5 \mathrm{mM} \mathrm{Mg}$ during the $1 \times 10^{-8} \mathrm{~g} / \mathrm{ml}$ PTX contraction lowered the muscle tension by $25 \%$. The degree of inhibition of PTX-induced contraction by $5 \mathrm{mM} \mathrm{Mg}$ was similar to that of H60K-induced 
contraction. Pretreatment of the muscle with $1 \times 10^{-6} \mathrm{M} \mathrm{D}-600$ for 15 min inhibited a contraction due to $3 \times 10^{-9} \mathrm{~g} / \mathrm{ml}$ PTX. Addition of $1 \times 10^{-6} \mathrm{M} \mathrm{D}-600$ during the $3 \times 10^{-8}$ $\mathrm{g} / \mathrm{ml}$ PTX contraction reduced the tension to the control level in $20 \mathrm{~min}$.

Addition of $3 \mathrm{mM}$ EGTA to the bath in the course of tension development by $3<10^{-9}$ $\mathrm{g} / \mathrm{ml}$ PTX lowered the tension to the control level in $30 \mathrm{~min}$. In the Ca-deficient medium with or without $1 \mathrm{mM}$ EGTA, the aorta did not exhibit contraction in response to $3 \times 10^{-9}$ $\mathrm{g} / \mathrm{ml}$ PTX and by adding 2.5 or $3.5 \mathrm{mM}$ Ca to the medium $20 \mathrm{~min}$ after the addition of PTX, tension developed in the aorta.

\section{Effects of PTX on isolated coronary and mesenteric arteries of dogs}

Coronary and mesenteric arteries of the dog were preliminarily conditioned by $\mathrm{H} 60 \mathrm{~K}$ and then PTX was applied. PTX induced contractions in dog mesenteric and coronary arteries are shown in Fig. $7 \mathrm{~b}$ and $7 \mathrm{c}$. Dose-response relation was observed in both muscles (Fig. 8). The rate of rise of PTX contraction in coronary artery was faster than that in the mesenteric artery or rabbit aorta at a concentration above $1 \times 10^{-10} \mathrm{~g} / \mathrm{ml}$ but slightly slower than that by H60K. PTX-induced contraction reached the peak tension in $10-15 \mathrm{~min}$ followed by a slow relaxation at $3 \times 10^{-9} \mathrm{~g} / \mathrm{ml}$, or in some cases, $1 \times 10^{-9} \mathrm{~g} / \mathrm{ml}$ in the coronary artery and at $3 \times 10^{-9} \mathrm{~g} / \mathrm{ml}$ in mesenteric artery (Fig. 7b, 7c). At a concentration below $1 \times 10^{-10} \mathrm{~g} / \mathrm{ml}$, contractile response in the coronary artery was slow and continued to rise for more than $1 \mathrm{hr}$. The minimum concentration of PTX required for contraction was $1 \times 10^{-11} \mathrm{~g} / \mathrm{ml}$ in the coronary artery which was the most sensitive to PTX among the vascular muscles used.

Adenosine at a concentration of $5 \times 10^{-5} \mathrm{~g} / \mathrm{ml}$ depressed $3 \times 10^{-10} \mathrm{~g} / \mathrm{ml}$ PTX contraction in the coronary artery by $50 \%$ but never competely even with a higher adenosine concentration $\left(1 \times 10^{-4} \mathrm{~g} / \mathrm{ml}\right)$.

\section{DISCUSSION}

In the present experiment we examined the pharmacological effects of PTX extracted from Palythoa tuberculosa on isolated smooth muscles. PTX induced contractions in both intestinal and vascular smooth muscles. The concentration of PTX required for the contraction in ileum (above $1 \times 10^{-10} \mathrm{~g} / \mathrm{ml}$ ), taenia coli (above $1 \times 10^{-10} \mathrm{~g} / \mathrm{ml}$ ) or blood vessels (above $1 \times 10^{-11}-1 \times 10^{-10} \mathrm{~g} / \mathrm{ml}$ ) was extremely low as compared to other stimulants; acetylcholine on intestinal smooth muscles $\left(1 \times 10^{-8} \mathrm{~g} / \mathrm{ml}\right)$, norepinephrine or epinephrine on vascular smooth muscles $\left(5 \times 10^{-9} \mathrm{~g} / \mathrm{ml}\right)$, histamine $\left(1 \times 10^{-8} \mathrm{~g} / \mathrm{ml}\right)$, serotonin $\left(1 \times 10^{-7} \mathrm{~g} / \mathrm{ml}\right)$, nicotine $\left(5 \times 10^{-6} \mathrm{~g} / \mathrm{ml}\right)$ in our experiment or prostaglandins $\left(1 \times 10^{-\theta} \mathrm{g} / \mathrm{ml}\right)(15)$, on both preparations.

The coronary artery of dog was the most sensitive to PTX, and contracted at a concentration of $1 \times 10^{-11} \mathrm{~g} / \mathrm{ml}$. Deguchi et al. (6) reported that PTX had a potent cardiotoxic effect and their data on ECG in cat showed bradycardia, ectopic beats, bigeminity, ventricular arrythmias, fall in ST segment and ensuing T inversion. Fall in ST segment and T inversion suggested the possibility of myocardial damage as a result of coronary insufficiency. Kaul et al. (8) reported that $5 \times 10^{-10} \mathrm{~g} / \mathrm{ml}$ PTX depressed coronary flow in isolated perfusing heart of guinea pig and suggested that the lethality of PTX was due to a profound coronary vaso- 
constriction. Further, Vick and Wiles (10) suggested that death by PTX was due to profound coronary vasoconstriction and cardiac failure. The highest sensitivity of coronary artery strip in this experiment is consistent with the suggestions of these authors.

Ineffectiveness of atropine, tripelennamine or tetrodotoxin on the PTX contraction of taenia coli and ileum and of phentolamine, phenoxybenzamine or atropine on rabbit aorta suggests that PTX acts directly on the smooth muscles.

Removal of PTX from the bathing medium during PTX-induced contraction did not alter the contraction, indicating the irreversibility of the PTX response. Further, the fact that the second application of PTX produced no contraction or only a weak contraction indicates the lack of reproducibility of PTX response.

Electrophysiological experiments showed that PTX depolarized the cell membrane of taenia coli and increased spike discharge. The magnitude of depolarization induced by PTX was similar or slightly larger than that of spontaneous activity. The excitatory effect of PTX in taenia coli was small when compared with that of H15K. During the prolonged PTX treatment, both the spike discharge and the contractile tension were gradually depressed. Magnitude of depolarization by PTX at this stage was less than that induced by H15K which induced both depolarization and increase in spike activity followed by a tension development. From these data, the inhibition of spike generation by PTX could not be a depolarization block.

The depolarizing effect of PTX was also observed in frog sartorius muscle (6). PTX appeared to have a depolarizing action in both skeletal and smooth muscles. Sometimes a small and complex or an abortive spike appeared after a long exposure to PTX at higher dose $\left(1 \times 10^{-8} \mathrm{~g} / \mathrm{ml}\right)$. Burnstock (16) reported that the small and complex spike was due to asynchronous excitation and an abortive spike was due to decrease in the number of firing cells when measured with the sucrose gap method. These results together with the absence of reproducible response by the second application of PTX suggest that after a long exposure to PTX, the excitation factor of the cell membrane is altered.

In taenia coli, the PTX-induced contraction was dependent on the spontaneous activity under isometric recording. Changes due to PTX in membrane potential also depended on the pre-existing spontaneous activity. On the other hand, the response to PTX under isotonic recording was independent on the spontaneous activity. This mode of action in taenia coli was different from other stimulants. In this regard, it is noteworthy that according to Bose (17) and Lüllmann et al. (18), ouabain also exhibited a contraction which was dependent on spontaneous contraction. Furthermore, Casteels (19) reported that the initial increase of spike frequency produced by ouabain was related to the spontaneous spike discharge of the tissue. In isotonic recording, Schatzmann and Ackermann (20) observed a dose-dependent contraction by ouabain in taenia coli. From these data, the response of taenia coli to ouabain was similar to PTX. We cannot explain why the spontaneously active muscle solely responded to PTX or ouabain. It is also unclear whether or not the mechanisms of action of PTX and ouabain on taenia coli are similar. It is speculated that the action of PTX on taenia coli is related to activities of the muscle, especially to the resting 
membrane potential or metabolic activity of the muscle.

Excess Mg and D-600 inhibited the PTX-induced contraction and PTX did not induce a contraction in Ca-free medium in taenia coli. Further, PTX-induced contraction was inhibited by D-600 or in a Ca-free medium in the aorta. From these results, $C a$ in the medium was required for PTX to induce a contraction. In rabbit ventricle, Rayner et al. (9) reported an increase in ${ }^{45} \mathrm{Ca}$ uptake by PTX. We have also observed that PTX increased the intracellular ${ }^{45} \mathrm{Ca}$ uptake in rabbit aorta (unpublished data). Thus it would appear that PTX-induced contraction is due to Ca entry into the cell.

\section{REFERENCES}

1) Kiml'ra, S., Hashimoto, Y. anit Yama7ato, K.: Toxicon 10, 611 (1973)

2) Kimura, S. and Hashimoto, Y.: Pub. Sefo. Mat. Biol, Lab. 20, 713 (1973)

3) Cierfazko, L.S. ani Attaway, D.H.: Res. Abst. The Pitrolom Res. Fund. Amer. Chem. Soc., p. 107, ciled from reference 8 (1961)

4) Moore, R.E. ANi Scheler, P.J.: Science 172, 495 (1971)

5) Deguchi, T., Aosimma, S., Sakai, Y., Takamatsl, S. and Urakalya, N.: Japan. J. Pharmacol. 24, Suppl. 116 (1974)

6) Deguchi, T., Urakawa, N. and Takamaisl, S.: Animal, Plant and Microbial Tuxins, Edited by Ohsaka, A., Hayashi, K. and Sawai, Y., Vol. 2, p. 379, Plenum Publishing Corporation, New York (1976)

7) Wiles, J.S., ViCK, J.A. AND CirisTM ISiN, M.K.: Toxicon 12, 427 (1974)

8) Kaut, P.N., Farmer, M.R. A.jd Ciereszko, L.S.: Proc. West. Pharmacol. Soc. 17, 294 (1974)

9) Rayner, M.D., Sandfrs, B.I., Harris, S.M., Lin, Y.C. and Morton, B.E.: Res. Commun. Chem. Path. Pharmacol. 11, 55 (1975)

10) VICK, J.A. AND WiL.F, J.S.: Toxic. appl. Phamacol. 34, 214 (1975)

11) Bülbring, E. And Burnstock, G.: Brit. J. Pharmacol. 15. 611 (1960)

12) Washrzu, Y.: Experiments in Physiology and Biochemistry, Edited by Kerklt, G.A., Vol, 2, p. 177, Academic Press, London (1969)

13) Golenhofen, K. And LoH, D.V.: Pflïgers Arch. 314, 312 (1970)

14) Fleckensthin, A., Tritthart, H., Filickfasthin, B., Herbst, A. and Gruex, G.: Arch. Pharmacol. 264, $227(1969)$

15) HorTox, E.W. Physiol. Rev. 49. 122 (1969)

16) Burnstock, G, : J. Physiol. 143, 165 (1958)

17) BOSE, D.: Brit. J. Pharmacol. 55, 111 (1975)

18) Lülmane, H, Lrakawa, N. and Zifglek, A.: Arch. Pharmacol. (in press)

19) Castelel.s, R.: J. Physiol. 184, 131 (1966)

20) Schatzainan, H.J. Ani) Ackiruavn, Il. Hell. physiol pharmacol. Acta 19, 196 (1961) 